\title{
Tipologías arquitectónicas singulares en la Ca- brera Alta integradas en el Paisaje antrópico del noroeste hispano: Patrimonio Cultural
}

\author{
Gaspar Fernández San Elías, José Luis Alonso Ponga, \\ Victoria Marcos Martínez, Ana Sofía Pérez Fernández \\ Universidad de León - Universidad de Valladolid
}

Artículo recibido: 10-5-2012 / Aceptado: 8-6-2012

RESUMEN: En este trabajo de investigación se realiza un estudio del valor patrimonial de las construcciones tradicionales que aún perviven en la Cabrera Alta (León, España). Abordamos el tema desde la interdisciplinariedad para conseguir abarcar toda la polisemia que encierran una serie de edificios comunes en la comarca.

El trabajo se ha realizado mediante la metodología más adecuada: el dibujo, el análisis tipológico y su complemento con la documentación histórica y bibliográfica pertinente. Ha exigido medir, comparar, analizar sus unidades elementales en relación a otras arquitecturas vecinales de la comarca, haciendo evidente su geometría y los mecanismos de restitución gráfica. Con este trabajo queremos penetrar de una manera científica en las claves estéticas, sociales y culturales de unos habitantes que mediante el dominio de la naturaleza y del entorno, en perfecta simbiosis con el medio, han sabido hacer frente a sus necesidades vitales. Las soluciones aportadas por la arquitectura tradicional, de poderoso atractivo artístico se basan en un saber a la vez culto y popular, hegemónico y subalterno que ha producido tipologías arquitectónicas resultantes integradas en el paisaje, que han creado, a la vez, una serie de productos patrimoniales.

Palabras clave: patrimonio, arquitectura tradicional, arte popular, paisaje antrópico, modelo constructivo, sistemas de carga, cubiertas de teito, esquistos, lajas pizarrosas, corredor, estructura, viga cumbrera, pie derecho.

RÉsumé: Dans le travail de recherche qui suit, on effectue une étude de la valeur patrimoniale des constructions traditionnelles qui survivent dans la Haute Cabrera (León-Espagne). Nous avons voulu aborder le sujet suivant un type d'approche interdisciplinaire pour arriver à comprendre la polysémie qui renferme toute une série de constructions communes à cette région.

Le travail a été réalisé en tenant compte de la méthodologie la plus appropriée : le dessin, l'analyse typologique et son complément avec la documentation historique et bibliographique pertinente. Elle nous a obligé à mesurer, comparer, analyser ses unités fondamentales par rapport à d'autres architectures vicinales de la même région, montrant, de façon évidente, sa géométrie et les mécanismes de restitution graphique. Avec ce travail nous voulons pénétrer, d'une manière scientifique, dans les clés esthétiques, sociales et culturelles de ces habitants qui, grâce à la maîtrise de la nature et de l'environnement, en parfaite symbiose avec son milieu naturel, ont réussi à affronter leurs besoins vitaux. Les solutions apportées par l'architecture traditionnelle, d'un énorme attrait touristique, se fondent sur un savoir faire à la fois savant et populaire, hégémonique et subalterne qui a produit des typologies architecturales résultantes, intégrées dans le paysage, et qui ont créé, à leur tour, un bon nombre de produits patrimoniales.

Mots clés: patrimoine, architecture traditionnelle, art populaire, paysage anthropique, modèle constructif, systèmes de charge, poitures de chaume, schistes, pierres plates en ardoise, corridor, structure, poutre de faitage, pied droit. 


\section{INTRODUCCIÓN}

La Cabrera es una comarca situada en el suroeste de la provincia de León entre los Montes Aquilianos, el Teleno y la Sierra de Pobladura que establecen los límites con el Bierzo y Maragatería; de la provincia de Zamora la separa las sierras de Cabrera y Peña Negra, en el oeste enlaza con la provincia de Orense y por el este con la Valdería ${ }^{1}$. Está divida en dos zonas, la orientada hacia la cuenca del Duero, llamada Cabrera Alta, y la que vierten sus aguas hacia el río Sil, La Cabrera Baja. El presente trabajo se centrará en La Cabrera Alta. De las dos sub-comarcas, esta es la más representativa, significativa y cuyo patrimonio arquitectónico corre más peligro de desaparición por el grado de despoblamiento y abandono.

En la Cabrera Alta existen 13 poblaciones: Baíllo, Corporales, Cunas, Iruela, La Cuesta, Manzaneda, Pozos, Quintanilla de Yuso, Truchas, Truchillas, Valdavido, Villar del Monte y Villarino. A partir de los cuales el paisaje natural ha sido antropizado y convertido en un paisaje cultural.

\footnotetext{
${ }^{1}$ Hay una serie de obras fundamentales sobre esta comarca entre las que destacan CASADO LOBATO M. C. (2002) (1948) El habla de la Cabrera Alta. Academia de la Llingua Asturiana. Úvieu. CARNICER, R.(2009) Donde las Hurdes se llaman Cabrera. Valladolid Ámbito Ediciones Ramón Carnicer, Valentín Cabero, CASADO LOBATO, Ma Concepción (2000): “El habla de la Cabrera Alta, contribución al estudio del dialecto leonés". C.S.I.C. Madrid, 1948; "La arquitectura de la Cabrera un tesoro sin valorar", León en Madrid, 359, pp. 18-20; --, (1980): "Ayer y hoy de la cultura leonesa", Tierras de León, 38, pp. 148. GARCÍA GRINDA, José Luis (2007): Arquitectura Popular Leonesa, León, 2 tom., pp. 167-180, León, 1991; "La Cabrera. Cuadernos de arquitectura". Instituto Leonés de Cultura. Diputación Provincial de León. SÁNCHEZ PALENCIA, F. Javier (2000): "Arqueología romana de la Cabrera", León en Madrid, Madrid, pp. 6-13. SÁNCHEZ PALENCIA, F. J../ FERNÁNDEZ POSSE, Mà D. (1985): La Corona de Corporales y el castro de Corporales 1. Truchas (León). Campañas de 1978 y 1981, EAE, 141, Madrid. CABERO DIÉGUEZ, Valentín (1980): “Espacio Agrario y economía de subsistencia en las montañas galaico-leonesas: La Cabrera". Instituto "Fray Bernardino de Sahagún", León, y Ediciones Universidad de Salamanca, Salamanca.
}

La emigración, el cambio de actividades económicas en las que la agricultura y la ganadería han dado paso a una minería no controlada por los habitantes han hecho que muchas de sus peculiares costumbres se difuminaran y desapareciesen para siempre. De todos modos, y pese a lo perdido, sigue siendo una de las comarcas más singulares de la comunidad castellanoleonesa. La potencia de su paisaje natural y agrario -allí donde no ha llegado la "fiebre de la pizarra"-; la presencia de una interesante arquitectura popular y vernácula en localidades como Villar del Monte, Pozos, Corporales, Truchas...; su rico patrimonio arqueológico de época prerromana y romana, con los castros de Corporales, Truchas,... hacen de esta comarca una de las más interesantes de todo el noroeste peninsular.

El presente trabajo estudia las tipologías de la arquitectura tradicional cabreiresa (casa pajiza, casa losada, casa de dos plantas, casa con corredor, casa con corredor y patín -escalera exterior-, pajares,... ) y su ubicación (en la ladera, en el valle, en torno a la iglesia o al camino) así como los materiales empleados (esquistos pizarrosos verdes, azules, negros, cuarcitas de colores, madera o cubierta vegetal); además analiza los factores que favorecen su integración en el ambiente natural: su sencillez técnica y sus soluciones simples; las circunstancias geográficas (altitud, climatología, geología...) y económicas (agricultura y ganadería); el uso de los materiales del propio entorno; la utilización de una escala natural, es decir, de la proporción humana, parámetro que pone de manifiesto la convivencia, integración y el carácter luchador cabreirés, formado por las adversidades del clima; los efectos plásticos; la "armonía por contraste" $^{\prime 2}$; constructores maestros albañiles populares y la ausencia total de procesos industriales en la construcción. Su antiguo

${ }^{2}$ Nos servimos de una expresión utilizada por ELÍAS PASTOR, L. V. y MONCOSÍ DE BORBÓN, R. (1978): Arquitectura Popular de La Rioja. Madrid. P. 27. 
aislamiento geográfico nos permite ahora, a través de su arquitectura tradicional, adentrarnos en las constantes y variables de sus ancestrales modos de vida.

\section{METODOLOGÍA}

La metodología de estudio de la arquitectura popular se basa, fundamentalmente, en el trabajo de campo que ha conllevado el siguiente proceso:

- Una visita previa a los núcleos tratados en la comarca, para hacernos una idea del valor arquitectónico, urbanístico y patrimonial de los edificios.

- Estudio de los archivos de los diferentes catastros, desde el del Marqués de la Ensenada hasta las contribuciones actuales que están en el Archivo Histórico Provincial de León.

- Consulta de obras clásicas, como el Diccionario Geográfico e Histórico de España y sus posesiones de Ultramar de Pascual Madoz, de estudios pioneros, como la obra de Torres Balbás, Carlos Flores y Luis Feduchi, y los últimos estudios de arquitectura tradicional leonesa de José Luis García Grinda, y otros actuales como los de los etnógrafos-investigadores Concha Casado, J. Caro Baroja, J.L. Alonso Ponga o Juan Carlos Ponga y Araceli Rodríguez.

- A continuación, hemos vuelto a desarrollar un trabajo de campo en el que hemos tomado las medidas, croquis, bocetos, fotografías...

- Sobre estas bases hemos desarrollado los planteamientos de nuestro estudio.

- Finalmente, hemos sacado las conclusiones, valorizaciones y perspectivas oportunas inducidas de este trabajo.

\section{LA ARQUITECTURA TRADICIONAL Y SU INTEGRACIÓN EN EL PAISAJE}

\section{Concepto de arquitectura tradicional}

Pueblo y popular son dos concepciones que, como señalaba Ortega y Gasset ${ }^{3}$, "permanecen nítidas mientras se mantengan en el estado de creencias y se vuelven más escurridizas y difícilmente aprehensibles a medida que se procura trasladarlas a la categoría de ideas"; por ello nos quedamos sin más con el concepto de que la arquitectura popular es la realizada por el pueblo, sin entrar en disquisiciones teóricas sobre ambos conceptos que, en este caso, no aportarían especial valor. Este concepto que en otras comarcas se vuelve más difícil de definir, aquí en La Cabrera Alta es más fácil, partiendo de que las limitaciones agrícolas-ganaderas, la escasa incidencia del comercio y el aislamiento secular han permitido el desarrollo de unas comunidades en las que ha prevalecido el concejo, o sea, el conjunto de los vecinos sobre los individuos. En muy pocas ocasiones se han producido entre sus miembros diferencias socio-económicas a favor de algún miembro de la comunidad.

La arquitectura es una de las manifestaciones a través de las cuales podemos estudiar un pueblo, entendiendo la arquitectura en el sentido más amplio de la palabra: como el intento del hombre por relacionarse con la naturaleza conquistando, o antropizando, el medio en el que se asienta. Desde este punto de vista, el concepto de arquitectura popular, como diría Kavanagh, lo tomamos "en un sentido amplio que incluye no solamente el diseño de los edificios, sino también la organización total del espacio económico y simbólico del pueblo o aldea, como conjunto"4.

${ }^{3} 1$ FLORES, C. (1974): Arquitectura Popular Española. T. III, Madrid, p 3.

${ }^{4}$ KAVANAGH, W. (1990) "La memoria colectiva como condicionante de la arquitectura popular" en CEA GUTIERREZ, A. FERNÁNDEZ MONTES, M; SÁNCHEZ GÓMEZ, L.A. Arquitectura Popular en España. Madrid, C.S.I.C. p. 55. 
El dominio del hombre sobre el medio se plasma en la ocupación del terrazgo, que se traduce en la ubicación de los asentamientos, buscando siempre las condiciones óptimas para el desarrollo de la vida de la comunidad. A ello ayudan también las posibilidades técnicas que posee el grupo y los conocimientos culturales que le permiten adaptarse a ambientes y habitats extremos.

Una arquitectura popular que, en La Cabrera, más que en ninguna otra comarca del país, tiene como fin satisfacer las necesidades de los miembros de sus comunidades. No hay edificio: vivienda, pajar, cuadra, cabaña de pastor, palomar, molino, cerramiento de cortinas y huertos, ermita o iglesia en La Cabrera Alta, que no tenga dicho fin; no como en otras comarcas, donde la arquitectura civil culta conformada por palacios o casonas, además de servir de morada y atender las necesidades económicas de tipo agrícola-ganadero o comercial, representan el poder político-económicosocial de sus moradores.

La variedad de fábricas, de plantas y alzados está en relación directa con la actividad ocupacional de los habitantes, pero también con la economía y, en especial, con el progreso, entendido este como desarrollo y avance de lo simple a lo complejo. Está en relación directa con las modas imperantes, lo que le dota de un dinamismo y unos cambios que se perciben en todos los núcleos cuando nos percatamos de la variedad de edificios que encontramos en ella. En buena medida, la evolución constructiva rural deriva como fruto de la imitación que hace de las construcciones de la ciudad. La arquitectura vernácula, como ya puso de manifiesto Roldán Morales ${ }^{5}$, está en una relación directa con los núcleos urbanos, en una posición de feedback según la cual hay un trasvase continuo, un viaje de ida y vuelta de la ciu-

${ }^{5}$ ROLDAN MORALES, F. P. (1992) "El lenguaje de la arquitectura popular", en Arquitectura popular de Castilla y León. Bases para su estudio. BAEZ MEZQUITA, J. M. Coord. Instituto de Ciencias de la Educación. Universidad de Valladolid. Valladolid. 66. dad al campo y de éste a la ciudad. El mundo rural imita los logros de la ciudad y el arquitecto urbano toma del mundo rural, más conservador, elementos que recrea y adapta a las necesidades urbanas. Esta relación de influencias no es nueva. Los cambios en la arquitectura rural se pueden demostrar desde que tenemos documentos arqueológicos o escritos. Sin embargo, desde el s. XIX con el romanticismo comienzan a fijarse por escrito, en una serie de publicaciones emanadas de la cultura hegemónica, unos edificios muy concretos que se proponen como ejemplos tipo, los mismos que, poco a poco, se convertirán en modelos paradigmáticos de una comarca, sentando las bases de unos "denominados" modelos autóctonos. A su vez, la cultura hegemónica asigna a la arquitectura popular las mismas características que a toda la cultura del pueblo, esto es, algo nacido de una sabiduría popular, incontaminada y, por lo tanto, ejemplo de una cultura ancestral que se mantiene igual a sí misma, que no cambia con el paso del tiempo. Paralelamente se seleccionan unos núcleos como prototipos que encarnan las esencias de la arquitectura tradicional.

En estos discursos teóricos, se valora como positivo el "aislamiento" de ciertas comarcas, La Cabrera entre ellas, ya que la dificultad en las comunicaciones protege estos valores autóctonos de cambios foráneos, de "agresiones", como denominan a cualquier intento de renovación de los edificios. Dicho aislamiento responde más a una teoría de los estudiosos que a la realidad, porque es fácil demostrar que siempre ha existido una relación con otras comarcas limítrofes, y de éstas con las vecinas hasta que llega a relacionarse con la nación. Por el contrario, se silencia o se minimiza el papel de la economía, la precariedad en la que han vivido los habitantes de las comarcas más conservadoras en el mantenimiento de la arquitectura tradicional. Como veremos más adelante, los modelos arcaicos desaparecen con el cambio de las condiciones económicas. 
La arquitectura popular en la cabrera alta engarzada con el entorno

La Cabrera Alta como comarca natural ha sido condicionada por sus pobres recursos económicos, por un clima y suelos desfavorables, por su aislamiento cultural, por una altitud elevada y, por ello, nos muestra la relación del hombre con la geografía, del individuo con el espacio.

Los poblados se mimetizan con la naturaleza. La intervención del cabreirés sobre el paisaje es tan antigua como su propia historia, tal y como se ha desarrollado en otros capítulos, y su concepción espacial es fruto también de la adaptación al medio según sus necesidades. Su paisaje es el reflejo de su historia. Como decía Julio Caro Baroja "Cada campo y cada campesino tienen detrás su propia historia: cada país y cada paisaje también, en consecuencia"6.

Es en este paisaje arquitectónico inventado por los pastores en el que mejor se evidencia la integración en el medio natural. En este proceso secular, el papel jugado por la arquitectura popular y/o por la arquitectura hidráulica es fundamental y esencial, al mismo tiempo que constituye su rasgo más pertinente. Haciéndonos eco de una expresión ya clásica de Fernando Chueca Goitia ${ }^{7}$ lo podíamos considerar como "su invariante más castizo". Como todas las arquitecturas tradicionales, se basa en la búsqueda de un equilibrio entre el dominio del medio, los materiales que brinda la naturaleza, la economía y los conocimientos de que disponen los maestros albañiles responsables del levantamiento de estas construcciones ${ }^{8}$.

${ }^{6}$ CARO BAROJA, Julio, El paisaje, género pictórico y fuente de conocimiento de la arquitectura popular, en CEA GUTIÉRREZ, A./ FERNÁNDEZ MONTES, M./ SÁNCHEZ GÓMEZ, L. A. (1990): Arquitectura popular en España, p. 5. Actas de las jornadas. 1-5 diciembre 1987. Consejo Superior de Investigaciones Científicas.

${ }^{7}$ CHUECA GOITIA, Fernando (1971). Invariantes castizos de la Arquitectura Española. Ed. Seminarios y Ediciones, S.A. Guadalajara. P. 24 y 29.

${ }^{8}$ Según las teorías de los estudiosos de la llamada arquitectura tradicional o popular. FLORES, C. La Ar-
Tradicionalmente se ha concebido la arquitectura popular como una de las características que definen mejor el carácter primitivo del pueblo cuando realmente en ese mundo se desarrollaba formando parte de un todo en donde coexisten el pensamiento mágico-religioso con el lógico-empírico, un mundo en el que la puerta, la naturaleza, el color, la forma, el símbolo... se incorporan, en palabras de Antonio Fernández Alba, "como una naturaleza participativa". Lo que la lleva a servirse de formas simples, donde la función, "los usos y los contenidos espaciales quedan integrados en su construcción para superar la necesidad" 9 . De tal manera que forma y función son una misma cosa, ya que la unidad que presentan los materiales y la concepción espacial conllevan unas formas predeterminadas por la función y por el papel que juegan en el entorno natural en el que se manifiestan. De este modo "construir una casa, como ordenar un pueblo, tiene para el grupo social un significado trascendente: hacer del lugar un ámbito moral", como reconoce Fernández Alba, en el que la forma del espacio se concibe como una referencia donde "la vida se inicia y sobre todo se perpetúa", muy alejada de otros planteamientos mercantilistas propios de arquitecturas modernas. Aquí, en la arquitectura primitiva, "la casa reproduce al pueblo y el pueblo se ve

quitectura Tradicional. FEDUCHI, L. (1974): “Itinerarios de Arquitectura Popular Española". T. La Meseta Septentrional. Barcelona. FLORES, C. (1974): "Arquitectura Popular Española". T. III, Madrid. GARCÍA FERNÁNDEZ, E. (1986): "León. Alfoces y pueblos". Colegio Oficial de Arquitectos de León. Madrid. TORRES BALBÁS. L (1934). "La vivienda popular en España" en Folklore y costumbres de España. Dirigido por ARRERAS CANDÍ., Barcelona. ALONSO PONGA. J. L. Arquitectura Popular en la Provincia de León. GARCIA GRINDA, J.L. Arquitectura popular leonesa. BENITO F. (1998) Arquitectura Tradicional de Castilla y León. Consejería de Medio Ambiente y Ordención Del Territorio. Salamanca.

${ }^{9}$ FERNÁNDEZ ALBA, A., "Los documentos arquitectónicos populares como monumentos históricos, o el intento de recuperación de la memoria de los márgenes", en CEA GUTIÉRREZ, A./ FERNÁNDEZ MONTES, M./ SÁNCHEZ GÓMEZ, L. A., (1990): “Arquitectura popular en España", p. 22. Actas de las jornadas. 1-5 diciembre 1987. Consejo Superior de Investigaciones Científicas. 
reflejado en la casa". Estas constantes se combinan entre sí de una forma arbitraria según una serie de variables que a su vez propician un número amplio e indeterminado de soluciones. Por eso las construcciones que hoy consideramos populares o tradicionales son tipológicamente muy variadas ${ }^{10}$.

Evidentemente no somos los primeros en acercarnos a la arquitectura de La Cabrera leonesa, si bien se ha de señalar que su estudio y conocimiento ha estado ausente en los grandes tratados de arquitectura española publicados por Luis Feduchi ${ }^{11}$ y por Carlos Flores ${ }^{12}$, quizás debido a que la personalidad arquitectónica de La Cabrera, por su aislamiento, quedó diluida en lo que se entiende por arquitectura leonesa, al tender a generalizaciones. Sólo últimamente ha sido puesta en valor por estudios y publicaciones como las de José Luis García Grinda ${ }^{13}$ que, si bien llegan un poco tarde, servirán sin duda para que la esencia de esta arquitectura primitiva se aplique a las nuevas edificaciones que se han hecho y se están haciendo en los mismos pueblos. Y ello, sin convertirse en tipologías, ni pretender conseguir un mimetismo perfecto con su entorno, o sea, con la filosofía de sensibilizar a los cabreireses y a sus autoridades políticas de la importancia que posee su patrimonio y de evitar la utilización de unos modelos arquitectónicos globalizadores y uniformes que, de seguir así, acabarán con la rica diversidad arquitectónica de la comarca. Publica-

\footnotetext{
${ }^{10}$ Para apreciar esta variedad sólo tenemos que fijarnos que en unos casos es el propio dueño quien las levanta en un alarde de autoconstrucción, sobre todo cuando hablamos de edificios pequeños y simples, y en otros, la mayoría de las veces, los autores son los alba-

${ }^{11}$ FEDUCHI, L. (1974): Itinerarios de Arquitectura Popular Española. T. La Meseta Septentrional. Barcelona.

${ }^{12}$ FLORES, C. (1974): Arquitectura Popular Española. T. III, Madrid.

${ }^{13}$ GARCÍA GRINDA, J. L. (2006): "La Cabrera. Cuadernos de Arquitectura". Diputación de León. Instituto Leonés de Cultura. León. Y del mismo autor Arquitectura Popular Leonesa. T. II. Diputación Provincial de León, (1991).
} ñiles. ciones a las que se añaden recientemente, en 2007, la de Concha Casado Lobato que lleva por título "La Cabrera y sus arquitectura Tradicional: materiales y tipologías"14. Tanto las publicaciones citadas como otras ${ }^{15}$ se basan casi únicamente en el análisis de las tipologías, análisis espacial y uso de materiales.

Esta comarca está hoy sometida a un fuerte proceso de patrimonialización que deberá estudiarse a medio y largo plazo y que nos permitirá observar de cerca las estrategias en la creación patrimonial y, sobre todo, los frutos conseguidos. No sólo por lo que respecta a una indudable recuperación de la misma, sino por lo que signifique como un hito en la prospectiva de la cultura tradicional de una comarca.

\section{Ubicación de los núcleos rurales}

En el estudio de la arquitectura tradicional es imprescindible tener en cuenta la ubicación de los pueblos. El asentamiento suele hacerse encaramado en la loma o en el fondo del valle. La elección del espacio determina hasta cierto punto el caserío y, en buena medida, propicia que se elijan una serie de soluciones constructivas, prefiriéndolas a otras.

La ubicación de los pueblos se relaciona también con el reparto del terrazgo, lo que a su vez ha sido responsable de una serie de construcciones básicas para el desarrollo de las tipologías. Es muy importante tener presente la historia de la economía y, sobre todo, la evolución de la población para poder valorar en su justa medida la Arquitectura Tradicional de La Cabrera.

La Cabrera es una zona de producción ganadera. La ganadería y el aprovechamiento del terrazgo han sido en buena

${ }^{14}$ CASADO, C. (2007): La Cabrera y su Arquitectura Tradicional: materiales y tipologías. Cuadernos de Arquitectura Popular $n^{0}$ 1. Junta de Castilla y León-Museo Etnográfico de Castilla y León. Zamora.

${ }^{15}$ PONGA MAYO, Juan Carlos y RODRÍGUEZ RODRÍGUEZ, Maㅡ Araceli (2000): Arquitectura popular en las comarcas de Castilla y León. Junta de Castilla y León, Consejería de Educación y Cultura, Valladolid. 
medida causantes de la creación de modelos constructivos (cuadras, pajares...), y los creadores de un espacio antrópico, cultural, mucho más importante que el espacio geológico por lo que a los aspectos socioculturales se refiere.

El espacio rural de cada uno de los pueblos se divide en varias zonas, que se complementan entre sí y que, por supuesto, no tienen la misma extensión. Al lado del pueblo, los cercados, los huertos, denominados en la lengua del país "cortiñedos", la denominación y su función nos remite a otras latitudes de la región leonesa: a las "cortinas" de Sayago, o los cortinales de Salamanca etc. Son claves en la economía familiar porque de ellos dependían los productos hortícolas bases juntamente con el cerdo de la alimentación familiar. Las cercas de los huertos, sin ser propiamente arquitectura, prefiguran el marco del núcleo rural. Más allá de los huertos, en tierra buena al lado del río, los linares, que producían el lino necesario para el autoabastecimiento de la unidad familiar, permitiendo a las mujeres manufacturar la fibra y aportar así un pequeño peculio que aligeraba algo las estrecheces del hogar. No lejos del pueblo donde el agua mana abundante, se sitúan las "llamas" o prados de guadaña, necesarios para el mantenimiento de los ganados. Junto a ellos los "chanos", para el cultivo del cereal panificable. Finalmente, en las zonas más alejadas, ya en el monte, los terrenos dedicados al cultivo del centeno, que seguían el sistema de "rozas"16, basado en la quema del monte sobre cuyas cenizas se sembraba directamente. Estas tierras "cuadriellas" eran comunales, roturadas también comunalmente. Forman parte de un modelo de aprovechamientos colectivizados, caracte-

${ }^{16}$ MARTÍN GALINDO, J.L. (1987) Poblamiento y actividad agraria tradicional en León: estudios de geografía rural; edición a cargo de Lorenzo López Trigal. Consejería de Obras Públicas y Ordenación del Territorio. Junta de Castilla y León Valladolid, p. 31 y ss. rísticos de algunas comarcas de la Provincia de León ${ }^{17}$.

Los núcleos de población se configuran como el centro, si no geográfico al menos simbólico del mundo rural, del que depende el resto del espacio y, lo que es más importante, desde el que se organiza cognitivamente el paisaje antrópico dominado por la comunidad.

La morfología de los núcleos urbanos está en función de su ubicación, generalmente en el fondo de los valles, lo que determina una tipología de pueblos que se alargan siguiendo el cauce de los ríos y ocupando la parte más apta del valle. Las pedanías más sobresalientes de La Cabrera Alta son Villar del Monte, Corporales, Iruela y Pozos, porque en ellas encontramos huellas de arquitectura antigua más o menos conservada, $y$, a través de ellas podemos hacernos una idea de lo que pudieron ser estos pueblos a finales del s. XIX o comienzos del s. XX. En La Cabrera Alta el caserío está más concentrado, más apiñado, desaparece casi el corral en las viviendas ${ }^{18}$ según se aprecia en lugares como Iruela y Manzaneda.

Pozos, en la vertiente sur de la Sierra del Teleno, se agarra a la ladera por la que asciende en calles estrechas y empinadas, defendidas por casas generalmente de dos plantas con las galerías cerradas por un tablazón apretado que ni deja entrar la luz ni pasar el frío. A las casas de dos plantas se asciende por escaleras exteriores. Los restos de cubiertas vegetales no pasan de ser testimoniales en un retroceso imparable.

\section{Los materiales}

La arquitectura cabreiresa usa los materiales que la naturaleza brinda generosa-

${ }^{17}$ ALONSO PONGA, J.L. (1999) Rito y sociedad en las comunidades agrícolas y pastoriles de Castilla y León. Junta de Castilla y León, Consejería de Agricultura y Ganadería. Salamanca p. 197 y ss. 355

${ }^{18}$ PONGA MAYO, Juan Carlos y RODRÍGUEZ RODRÍGUEZ, Maa Araceli (2000): Arquitectura popular en las comarcas de Castilla y León. Junta de Castilla y León, Consejería de Educación y Cultura, Valladolid. 
mente al campesino, ordenándolos "desde la racionalidad de su materia"; con ellos construye formas y espacios relacionados con la vida, alejada de composiciones preestablecidas y constituye el determinismo geográfico (altitud, climatología, geología) de la construcción y su integración en el ambiente natural. Esta afirmación no se contradice con lo anteriormente expuesto, esto es, que la propia geografía está mediatizada por la cultura que engloba aspectos económicos, o por el propio clima, que obliga al aprovechamiento reiterado de unos materiales y determina su colocación.

Los materiales que mejor definen el paisaje y conforman la estética de los núcleos rurales son los pétreos, esquistos verdosos, azules, negros o rojizos, cuarcitas de colores y lajas pizarrosas de gran variedad de tamaños y de colores para las paredes de las casas, arcilla y las losas ("llousas") ${ }^{19}$ de pizarra en las cubiertas y en las chimeneas. Son característicos los muros de hiladas de cantos rodados irregulares unidos con barro del terreno

Esta variedad de materiales, con una gama de colores tan abundante, da a los pueblos una vistosidad y elegancia particulares, al tiempo que los individualiza, porque no en todos los lugares afloran las mismas vetas y por consiguiente cada núcleo tiene unos colores dominantes. En Iruela aparecen edificios llamativos que han hecho del aprovechamiento de los materiales del terreno un reclamo de la belleza de esta comarca cuando se combinan perfectamente las materias primas: a los cantos de cuarzo se le añaden las pizarras, que combinan o contrastan, según los casos, con la roca madre del piso donde se asienta la localidad.

El barro es un material imprescindible en todo tipo de construcciones. Aquí se

${ }^{19}$ CASADO LOBATO, C. (1948) (2002) El habla de la Cabrera Alta. Academia de la Llingua Asturiana. Uvieu. p. 89 y ss. utiliza como mortero ${ }^{20}$, y en el interior de las casas como refuerzo de los muros de varas entretejidas que sirven de separación entre la cocina y las habitaciones. Se emplea con más intensidad en la construcción del horno. La madera de castaño se utiliza en los dinteles de los huecos puertas y ventanas. La más empleada es el roble que superabunda en el cierre de los corredores con entablados verticales, que produce una fisonomía típica comarcal ${ }^{21}$.

Pero el material más llamativo ha sido el "teito" o cuelmo, con el que se cubrían las techumbres de paja ("paya"). Es la paja del cereal, casi siempre centeno, que después de majado -desgranado con el mayal- se empleaba para techar.

\section{Construcciones}

La ausencia total de procesos industriales en su construcción es uno de los factores arquitectónicos integradores en el ambiente natural.

La Arquitectura tradicional se divide de una forma arbitraria que quizás sólo sirva para intentar un nomenclátor de edificios en la vivienda, la casa, y las construcciones auxiliares. Desde una perspectiva "etic", la vivienda es el edificio más importante, pero cuando investigamos con una perspectiva "emic", entonces nos damos cuenta de que la arquitectura más importante es la que denominamos "auxiliar", a veces "secundaria", porque sobre ella descansa la economía doméstica. En pocos sitios se ve, como aquí, que dentro de las construcciones se puede

\footnotetext{
${ }^{20}$ Los usos del barro en la construcción son varios, uno de ellos es el utilizarlo como mortero para unir otros materiales más duros, como en este caso. El color de este material puede matizar los colores de las construcciones de manera que a veces núcleos que utilizan los mismos tipos de piedra aparecen con coloridos diferentes frutos del barro que se ha empleado en la unión de las piezas. Cfr. ALONSO PONGA J. L (1994) (1989) (1986) La arquitectura del barro, Valladolid Junta de Castilla y León.

${ }^{21}$ TEMIÑO LÓPEZ-MUÑIZ, Mํㅗㄴ Jesús, (2009): Los Molinos de la Cabrera Leonesa. Fundación Monteleón.
} Burgos 
diferenciar el valor simbólico, de estatus, que funciona hacia fuera, cara a los otros, al público, y el valor económico, que sustenta al anterior, que se basa en la capacidad de producir bienes de consumo. Este campesino que mira hacia adentro, hacia la aldea, que no tiene relaciones de largo alcance con el exterior lejano, con la cabecera de comarca o con la capital de provincia, es más fuerte que el primero, quizás, obligado por la precariedad de sus medios de producción.

Los edificios son de varias formas, pero los estudiosos en un esquema operativo, que no agota toda la riqueza y variedad que representan, hablan de dos tipos: la vivienda y las construcciones auxiliares. Estas son las arquitecturas secundarias, denominadas así porque están en una relación de dependencia y de subordinación con otras lógicamente denominadas principales. La casa es concebida como elemento central de la configuración del espacio urbano, lo cual es indiscutible, pero parte de la importancia simbólica que se da a la vivienda va en detrimento de otros edificios. Las construcciones auxiliares -las cuadras, los pajares, los palomares, las fraguas, los molinos...son base y centro de la economía, lo que les hace ser más apreciadas, desde una visión "emic", que la propia casa. No es nuevo que en la mentalidad popular, precisamente por la precaria economía de supervivencia, las construcciones principales sean aquellas dedicadas a las actividades económicas.

La vivienda

En La Cabrera Alta las construcciones destinadas a la vivienda son de varios tipos, que están en función de la planta y el alzado, aunque se suelen resumir en dos tipologías básicas relacionadas con el Bierzo ${ }^{22}$.

En la actualidad se distinguen dos tipos de casas: desde el punto de vista de la cubierta, las de teito y las de losa, y, desde el punto de vista de las plantas, las de una

22 ALONSO GONZÁLEZ, J. MAGALLANES PERNAS, A (1979). "La vivienda rural de las Cabreras leonesas", 1aㅡ parte. En Tierras de León, nº 34-35. León o dos. O las de una planta y las de planta y piso. Si bien es verdad que las de una planta pueden estar cubiertas con paja o pizarra, las de dos siempre lo están con losa. Estamos hablando de dos modelos, uno más arcaico que el otro, que durante su evolución han convivido en un periodo muy corto, admitiéndose comúnmente que las casas de una sola planta se utilizan como cuadras y pajares hasta que cambian las modas. Esta evolución se produce a veces como un edificio que queda fuera de la vivienda. En otras ocasiones estas construcciones se quedan en un rincón de la nueva estructura, como ampliación de la casa pero dentro de la misma "corte", utilizando un lenguaje medieval.

García Grinda habla de la "casa de paja" y de la "casa de corredor", la primera de una sola planta y la segunda de dos. La denominación obedece en el primer caso a que se toma la cubierta como lo más significativo, mientras que en el segundo la clave se centra en el corredor.

Los últimos estudios llevados acabo por los investigadores nos muestran que la casa de teito está en franco retroceso. Algunos afirman que "La casa de "teito" de La Cabrera es hoy un tipo francamente raro del que sólo se ha podido identificar algún ejemplar aislado"23, pero matizan que lo que ha sucedido es un cambio de uso en el antiguo edificio, ya que las antiguas casas de teito se han convertido en "palleiros" y cuadras. Son las casas de una sola altura, de planta rectangular. Con un espacio de habitación dividido a su vez en otros dos, la cocina y el cuarto, y la cuadra para los animales. Con todo La Cabrera Alta ha sido la más resistente a los cambios y ha conservado un mayor número de casas, palleiros y cuadras de teito. El cambio de uso de los antiguos ejemplares ha llevado a que ahora sólo encontremos la cubierta de paja en algunas arquitecturas auxiliares como revelan

${ }^{23}$ GARCÍA GRINDA, J.L. Arquitectura Popular leonesa. p. 68 
los trabajos de campo realizados ya en este siglo ${ }^{24}$.

La vivienda, sin embargo, es el simbólico central; desde él se interpreta el urbanismo y en función de la casa deben entenderse las construcciones auxiliares, cuya ubicación está unida a la planta principal o lejos de la misma, agrupadas en barrios o diseminadas por la periferia del pueblo.

Vivienda de una sola planta

Alonso González nos dice que la casa de una sola planta esta levantada con "paramentos de poca altura", se caracteriza también por tener el "techo de paja y escasez de vanos". Esta vivienda puede pasar a constituir una vivienda de una sola planta pero con techo de pizarra, dando una "forma cuadrangular dividida al interior en dos partes separadas por un tabique cañizo, con una puerta, la cual comunica al hogar con la cuadra o corte, que a su vez tiene una puerta al exterior" 25 .

El modelo constructivo, según el autor citado, es colocar "sobre los muros laterales" las tijeras, teixeiras, formadas por gruesos troncos, construidas de forma que sostienen la viga cumbrera. Las teixeiras apoyan en maderos tirantes perojas, que descansan sobre el muro. Paralelamente a la viga de la cumbre se colocan una serie de troncos, llantas, que van sujetos a los canteiros por ataduras de caña o cuerda. Sobre las latas se colocan los cuelmos o las llousas. El diferente material utilizado en la cubierta nos da dos palabras para denominar el tejado; así al de losa lo llaman llouxan y al de paja, colmao. En los de paja los haces de

${ }^{24}$ PONGA MAYO, J., C.; RODRÍGUEZ RODRÍGUEZ, Ma A. (2000) Arquitectura Popular en las comarcas de Castilla y León. , p. 100-101.

25 SERVICIO DE PUBLICACIONES de la Excma. Diputación Provincial... p. 38 cit. En ALONSO GONZÁLEZ, J. MAGALLANES PERNAS, A (1979). "La vivienda rural de las Cabreras Leonesas", 1르. parte. En Tierras de León, nº 34-35. León cuelmo se atan a las llatas por medio de velortos o vilortas ${ }^{26}$.

Según García Grinda, a finales del s. XX la casa de paja ya ha desaparecido porque los ejemplares que quedan se han convertido en pajares, en una evolución lógica "facilitado por su escasa compartimentación interior y su elementariedad". Los ejemplares que documenta -según él- eran de una sola planta, con dos espacios de habitación, la cocina y el cuarto, además de la cuadra.

La parte central de la casa de una sola planta es la cocina, y dentro de ella el "llar" donde se hace el fuego sobre un enlosado. Como en los demás viviendas cubiertas con materia vegetal en ella, el humo salía por un "buraco" abierto en el teito, o simplemente por entre el teito. La separación, como se ha dicho, se hacía con tabiques de varas entretejidas revocadas con barro y encalados. Es el mismo sistema que se emplea en el Bierzo ${ }^{27}$. En el S. XIX aún se conservan muchos pueblos con construcciones de una sola planta y cubierta de teito, como se puede ver en los informes que nos da Pascual Madoz ${ }^{28}$. Medina Bravo, que escribe en el primer tercio del s. XX, constata que por entonces las casas de teito estaban desapareciendo con mayor rapidez que en épocas anteriores.

En su artículo La vivienda rural en La Cabrera Leonesa ${ }^{29}$, Joaquín Alonso González alude a la tipología de las casas según las publicaciones anteriores, pero aporta los datos obtenidos de los servicios de la Dipu-

${ }^{26}$ ALONSO GONZÁLEZ J, GONZÁLEZ PERNAS. La vivienda tradicional en Las Cabreras Leonesas p. 95.

${ }^{27}$ ALONSO PONGA, J. L. y DIÉGUEZ AYERBE A. (1984) El Bierzo. Etnografía y Folklore de las comarcas leonesas. Ediciones Leonesas, Santiago García Editor. León, p. 18.

${ }^{28}$ MADOZ, P. (1845-1850) (1983) Diccionario Geográfico- Estadístico-Histórico de España y sus posesiones de Ultramar. Madrid. Ed. Ámbito, Valladolid.

${ }^{29}$ ALONSO GONZÁLEZ y J. GONZÁLEZ PERNAS. La vivienda tradicional en Las Cabreras Leonesas....... Vol. II. 
tación Provincial ${ }^{30}$, resumiendo la tipología en: viviendas de una planta, viviendas de dos plantas con escalera exterior y viviendas de dos plantas con escalera exterior pero con acceso desde el corral, siendo esta última variante la más moderna. La casa de dos plantas destaca por el empleo del corredor como elemento más característico.

Aporta excelentes datos para demostrar la evolución en la vivienda, basándose en los datos del Catastro del Marqués de la Ensenada, elaborado en esta zona entre 1752 y 1753. Por este excepcional documento sabemos que, a mediados del s. XVIII, las casas que tenían entre cuatro y siete compartimentos eran 20, había 38 que tenían entre dos y cuatro divisiones, y las que tenían una sola alcanzaban hasta 23. Esta relación se completa con las medidas de la fachada. La mayoría, hasta un número de 46 , tenían entre cinco y diez varas de frente, 33 viviendas medían frontalmente entre diez y veinte varas; solamente siete tenían entre veinte y treinta, y entre treinta y cuarenta apenas dos.

Concluye que en la época de Ensenada hay un porcentaje de casas del $52,38 \%$ de una sola planta y un $47,61 \%$ de casas de alto y bajo. La evolución se constata no por razón de oficio o profesión, sino "por razones de mejora económica". Es un documento excepcional para demostrar la evolución de la vivienda, y de la arquitectura tradicional en general $^{31}$. La evolución se ha dado siempre, y se sigue produciendo ahora, lo que sucede es que en esa evolución en la que las tipologías más arcaicas van quedando en desuso

30 SERVICIO DE PUBLIACIONES de la Excma. Diputación Provincial de León. Informe de las Cabreras Leonesas. División Político Administrativa. León 1965. 03. 29.

${ }^{31}$ El cambio en la tipología de las plantas, la evolución de las casas se puede demostrar si comparamos los datos del catastro con los de las comprobaciones hechas una década después. Esto no sólo sucede en La Cabrera, acontece en muchos sitios, se puede ver en zonas cercanas como el Bierzo, o los Ancares, y tan alejadas como la Tierra de Campos o la ribera vallisoletana del río Esgueva. por obsoletas, se crean nuevos modelos que en unas generaciones pasan a ser el prototipo de la vivienda "arcaica", de manera que en el estudio de la arquitectura tradicional es conveniente tener presente la datación de las construcciones con las que estamos trabajando.

\section{La casa de dos pisos o casa de corredor}

Obviamente las dos plantas diversifican bastante más los espacios. En la superior se coloca la cocina con las habitaciones que mantienen los tabiques de encestado con barro y cal, aunque poco a poco, desde comienzos del s. XX, empiezan a hacerse de otro material más consistente. En la planta baja están las cuadras aunque a veces se colocan fuera de la vivienda, pero cercana a ésta, los espacios para las herramientas, el "alpendre" para el carro, la leña y el gallinero. La planta baja tiene una puerta grande protegida por el corredor saliente en función del paso de los animales y del carro ${ }^{32}$.

Este tipo de casa es parecido a algunos del Bierzo que J. $\mathrm{M}^{\mathrm{a}}$ Luengo Martínez ${ }^{33}$ denominaba casas serranas. El investigador berciano señala que este modelo está dotado de una chimenea, por oposición a la de teito, que carecía de ella.

Varios son los elementos característicos de este modelo de vivienda, pero los más sobresalientes son las escaleras de acceso al segundo piso, el corredor y el horno.

La escalera exterior, según Casado Lobato, "es algo genuinamente característico de la arquitectura popular de La Cabrera Alta" ${ }^{\prime 34}$. Sin embargo algunas familias acomodadas tenían escalera interior, lo que se

32 CERrato, A.; ORTEGA, P., "El patrimonio arquitectónico de La Cabrera" en Revista de Folklore, Fundación Joaquín Díaz, Valladolid, 2003, p. 90.

${ }^{33}$ LUENGO MARTÍNEZ, J. Ma․, Esquema de la arquitectura civil en el Bierzo. León, 1946, p. 11.

${ }^{34}$ CASADO LOBATO, C., (1948) El habla de la Cabrera Alta, p. 90. 
consideraba un pequeño lujo ${ }^{35}$. En ocasiones existen escaleras que tienen un arranque común.

Los dos pisos obligan a la construcción de la escalera de acceso colocada siempre al exterior. La escalera exterior o "patín" se coloca generalmente en paralelo a la fachada (Pozos), aunque a veces se coloca perpendicular a esta (Grinda).

La escalera de acceso va a dar al corredor y está compuesta de grandes sillares de losa, escalera sin pasamanos (Alonso González).

El corredor. El centro de todo es el corredor, que se coloca en el lado más largo orientado a la solana. Sirve como desahogo de la casa y para contener el horno. Se forma por el volado de las vigas del piso reforzado, cuando es necesario con tornapuntas, como se puede observar en Villar del Monte y Pozos. El corredor está cerrado por tablas, aunque no faltan pequeñas ventanas a modo de tragaluces. A veces aparece algún tipo de balcón corredor con barandillas decoradas, pero es bastante raro. La climatología extremadamente dura propicia este tipo de corredores que con frecuencia destacan por su tosquedad, lo que no significa que no tengan cierta belleza que nos remite a categorías estéticas basadas en una rusticidad que se puso de moda también con el romanticismo.

Es la parte de la casa donde abunda más la madera; en ocasiones, en tipos más modernos los corredores abiertos están formados por columnas con zapatas bien trabajadas, como es el caso de La Cuesta.

El horno. Forma parte de la estructura de la vivienda tradicional cabreiresa. Es un añadido a la cocina, su volumen semicircular sobresale en la galería de la fachada mayor, o en uno de los laterales. Con frecuencia la meseta, sobre la que se coloca dicho horno, se sostiene sobre unos maderos en voladizo, pero no faltan ejemplares en los

${ }^{35}$ CERRATO, A.; ORTEGA, P., (2003) El patrimonio arquitectónico de la Cabrera. p. 90 que esta sujeción se refuerza con unos pies derechos, o con tornapuntas que apoyan en piedras salientes del mismo edificio.

Una construcción llamativa es la denominada "casa del forno", o sea, una construcción dedicada solamente a este elemento. La "casa el forno" en Villar del Monte es uno de los ejemplares más llamativos, no solo por la figura del horno montado sobre una plataforma sobre la que descansa el propio horno que muestra al exterior su cúpula, sino por la forma de cubierta, en un tejado de pizarra que desciende en un solo faldón.

Es una construcción tan característica que configura y da personalidad al paisaje urbano. Así sucede en Quintanilla de Yuso donde forman "un bello conjunto de volúmenes y material ancestral enraizado en el medio ancestral que los creó" ${ }^{\prime 36}$.

Chimeneas. La salida del humo se hacía a través de la chimenea. La casa primigenia no tuvo chiminea, de modo que los humos se perdían por la estancia entre el colmado o el llousao. (Alonso González). Las que actualmente encontramos están recubiertas de losas, dispuestas en escamas, con armazón de madera. Son de llamativos volúmenes prismáticos o troncopiramidales, de secciones cuadradas o rectangulares, rematados con un sombrerete de lajas de pizarra, el mismo material que aparece en las paredes de las chimeneas. No faltan lugares en los que el humo sigue saliendo por la "garroteira" o por el buraco del techo, como sucedía en las casas de teito (A. Cerrato). Existen varios tipos aunque abundan las piramidales truncadas protegidas con una losa en la parte superior -para impedir la entrada de agua y nieve- con un hueco o más en cada una de las caras, para facilitar la salida de humos y su función como respiradero. Sobresale una Chimenea escalonada en Villar del Monte cubierta de pizarra (véase Fig. 9); los faldones sobresalen de forma ascendente. Al igual que en Corporales don-

${ }^{36}$ CERRATO A.; ORTEGA, P. (2003) El patrimonio arquitectónico de la Cabrera, p. 90. 
de encontramos una chimenea de pizarra dividida en dos cuerpos por otra horizontal que sobresale y es paralela a la que cumple función de cobertor" 37 .

Construcciones auxiliares

\section{Pajares}

El pajar es construcción imprescindible en una economía agropastoril como la de esta comarca. Son construcciones rectangulares destinadas a almacenar la paja y la hierba para los animales. Cubiertos a doble vertiente con un bocarón en el techo para facilitar el almacenaje de la hierba. Muchos de ellos tienen su origen en antiguas casas de un solo piso reaprovechadas para esta función. Se construyeron lejos de las viviendas (obsérvese su implantación en la Fig. 13). Algunos inves-tigadores afirman que se ubican equidistantes entre la vivienda y la cuadra, buscando la máxima comodidad para el propietario.

Los pajares de Corporales presentan ejemplares con el boquerón en la línea alta de la fachada posterior que propicia mayor comodidad para la entrada de la yerba; en algún caso, el boquerón se abre en uno de los testeros, aprovechando también el desnivel del terreno. Esta solución se encuentra en varios ejemplares de la Maragatería ${ }^{38}$.

Es famoso uno en la localidad de Corporales que llama la atención por la bicromía de piedras pizarrosas y cuarzos (denótese en fig. 5), con uno de los testeros donde se aprecia aún el escalonamiento de una primitiva cubierta, realzada posteriormente para aumentar su capacidad. En este pajar es significativa la cruz hecha con las piedras blancas, que aquí, como en todas las construcciones auxiliares, son signos apotropaicos de protección, en este caso de la hierba necesaria para la alimentación del ganado y

${ }^{37}$ Ibid. p. 100.

38 GARCÍA GRINDA, J.L. (2005) "Función y forma: La arquitectura auxiliar agropecuaria leonesa" en La Arquitectura Tradicional en Tierras de León. León, Fundación Hullera Vasco-Leonesa p. 28. por lo tanto para mantener unos niveles de economía dignos, dentro de la pobreza de la comarca.

Los pajares de Villar del Monte tienen testeros escalonados, lo que facilitaba el apoyo de las vigas para montar la techumbre, y hasta servía de cortafuegos muy elemental para combatir los problemas de incendios abundantes y generalizados en todos los núcleos de cubiertas de paja.

\section{Los palomares}

Testimoniales son también los palomares. Las noticias que se tienen de ellos son escasas. Apenas queda el recuerdo de uno de ellos en Iruela. La tipología es como la mayoría de los del noroeste, similar a los de La Cabrera Baja y parecidos a algunos del Bierzo. De silueta circular, con tejado a un agua y con guardavientos que se forman por el realzado de las paredes circundantes. Tienen el paso de las palomas por las troneras. El tejado está a mediodía, y la tronera se produce por resalte del tejado.

\section{Los colmenares}

Son cercas de paredes de piedra que protegen los troncos huecos en los que enjambran las colmenas.

\section{Fraguas}

Comunal ha sido hasta no hace mucho tiempo, la fragua, por eso se situaba en un edificio a parte. El oficio de herrero, que con frecuencia incluía también el de herrador, era imprescindible para el desarrollo de la vida en las aldeas pueblos y villas leonesas. El herrero arreglaba los aperos de labranza, calzando las rejas, recortando los carros cuando era necesario, haciendo los clavos de gran tamaño para clavetear las vigas, etc. En los pueblos grandes el herrero podía ser el propietario de la fragua, pero en los pequeños la fragua era del común con lo que se veían en la necesidad de contratar los servicios de este profesional generando una serie de contratos y de redes clientelares que se reflejaban en contratos verbales, e incluso se plasmaban en las ordenanzas que 
posteriormente se elevaban a la categoría de leyes.

El edificio de la fragua suele ser un edificio emblemático, aislado para evitar los peligros que se derivan del uso del fuego. Geometría sencilla, de planta rectangular, de características y materiales idénticas a la arquitectura popular y cubiertas de losa. Existe un ejemplar en todos los pueblos. Tienen un ventano tronera para salida de humos y ventilación sobre todo en el invierno en el que el clima pedía cerrar la puerta. La fragua es, además un lugar comunal, de reunión informal, sobre todo en los días en los que la labor del campo no apuraba mucho al campesino. El refrán es muy elocuente en este caso "días de agua, taberna o fragua". Por eso el mundo de relaciones alrededor de este edificio es de gran importancia y sirve en buena medida para comprender la población en la que estamos.

No existen las bodegas como lugares diferenciados de las casas en La Cabrera Alta, la altitud no es propicia para el cultivo de la vid, a no ser en casos y ocasiones apuradas en las que se echaba mano de cualquier lugar en el que pudiese fructificar, aunque fuese sin muchas pretensiones, la vid. Sabemos que el cultivo de este producto que si existe en la Edad Media, se abandona ya en la Baja Edad Media ${ }^{39}$ porque la producción no es rentable y es más eficaz comprar el vino en otras latitudes, o al menos la uva.

\section{CONCLUSIONES}

Hemos reservado este apartado para plasmar las principales conclusiones de la investigación y se han agrupado en función de los objetivos planteados inicialmente.

La arquitectura tradicional conserva unas características que hacen de ella una de las señas de identidad más singulares de la comarca. Tales características hunden sus raíces en los valores más auténticos de lo

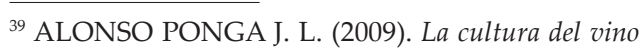
en la Provincia de León. León Edilesa, Diario de León. Vol. I, p. 18 y ss. popular y permanecen ajenas a soluciones importadas del exterior. Las construcciones rurales, en su volumetría y distribución en planta, son muy elementales. Sus proporciones denotan una realización a escala de la persona, atendiendo a principios pragmáticos y lógicos. El espacio interior está concebido como una unidad cerrada, donde se manifiesta el sistema económico autárquico y el rigor del clima. No hemos hallado casas blasonadas.

- Las construcciones auxiliares: pajares, fraguas, ... se asientan en zonas aisladas. Los molinos harineros comunales se caracterizan por su pequeño tamaño y por poseer una sola boca; la base de su construcción son materiales pétreos. Se encuentran ubicados en paisajes bien conservados, pero se enfrentan a su desaparición, debido a una tecnología tradicional no competitiva y a la consiguiente pérdida de vitalidad.

\section{PERSPECTIVAS}

El paisaje cultural de La Cabrera se ha visto bruscamente alterado por las explotaciones mineras de pizarra, de manera que es urgente una reconceptualización que nos permita salvar lo que aún nos queda, y ponerlo en valor en la medida que ello sea posible. La arquitectura tradicional aún es una constante en muchos municipios. Desde hace varios años se han creado asociaciones culturales que han conseguido llamar la atención de la riqueza que tiene esta comarca. Y lo han hecho fundamentalmente a dos niveles, uno mediante publicaciones monográficas en libros revistas y periódicos, y otro en trabajos de restauración y rehabilitación de algunos conjuntos que hoy día se levantan como hitos en el 'paisaje cultural

Sin embargo y a pesar de todo hay que seguir llamando la atención sobre los valores de un territorio que nos ofrece, aún en la actualidad, uno de los paisajes culturales más llamativos de la península. Ello se debe a que conserva en los núcleos de población buenos elementos arquitectónicos 
y conjuntos de edificios que nos muestran los modelos de vida de sus habitantes antes del éxodo de los vecinos. Pero el quilibrio es muy frágil. El paisaje agrario ha cambiado por el cambio de actividad económica. Los palomares, colmenares, molinos, pajares etc. al carecer de valor económico corren el riesgo de ser abandonados a su suerte, como ya está sucediendo, con lo que la ruina y desaparición se enseñorearán pronto en toda la comarca. Los dueños de la arquitectura civil no ven la necesidad (quizás tampoco es su misión) de invertir en restauración de edificios que ya no tienen sentido para ellos. Cada vez son más los que optan por arquitecturas que no tienen que ver con las formas tradicionales, ni con los materiales típicos cabreireses. Por ello y para una mejor conservación de este patrimonio que no es personal, sino social, que no es ni siquiera comarcal (aunque está en una comarca definida) sino regional y/o nacional es necesario hacer buenos proyectos de valorización de un patrimonio material e inmaterial que debe de ser utilizado como fuente de riqueza para el desarrollo de la comarca a través de la puesta en valor de lo elementos más característicos de la misma. Debe servir al mismo tiempo para crear discursos de patrimonio inmaterial que ayuden a comprender la historia de los diferentes núcleos rurales y con ellos de toda la comarca. Que nos ayuden a desvelar y comprender las leyendas, las tradiciones que acompañan a la arquitectura y a la vida en los pueblos; al paisaje natural que con la acción del hombre se convierte en paisaje cultural, y mediante una buena puesta en valor deviene en Bien de Interés Turístico generador de riqueza. 


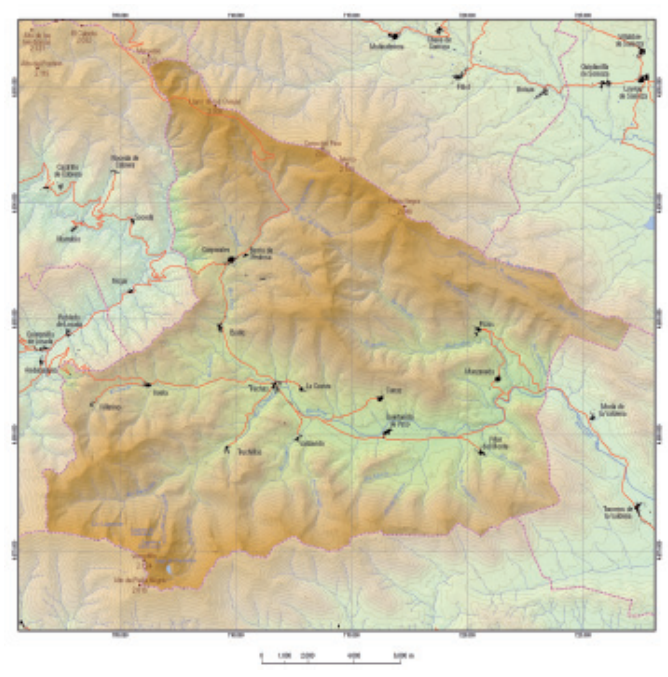

- Fig. 1. La red hidrográfica, determinante en la ocupación del territorio. Las formas más representativas de los emplazamientos son en valle y media ladera.

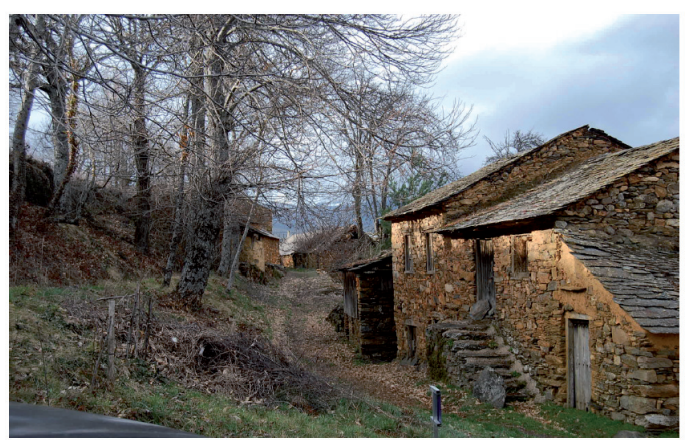

- Fig. 3. La arquitectura y su integración en el paisaje es uno de los aspectos más enraizados con la identidad de la comarca.

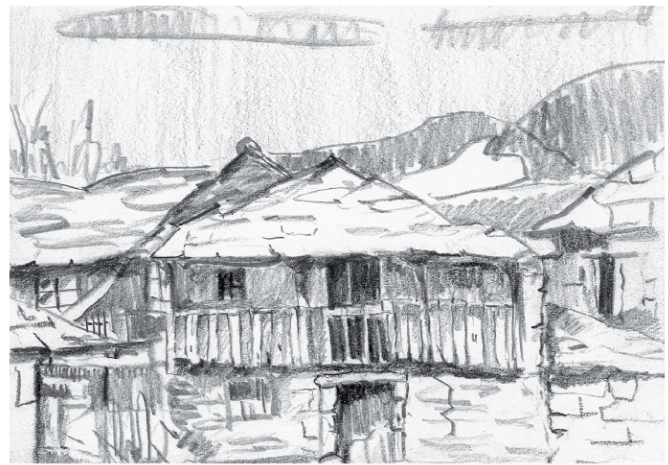

- Fig. 2. Boceto de vivienda de dos plantas ubicada en Truchas, que, de modo excepcional a la tipología analizada, no presenta escalera exterior.

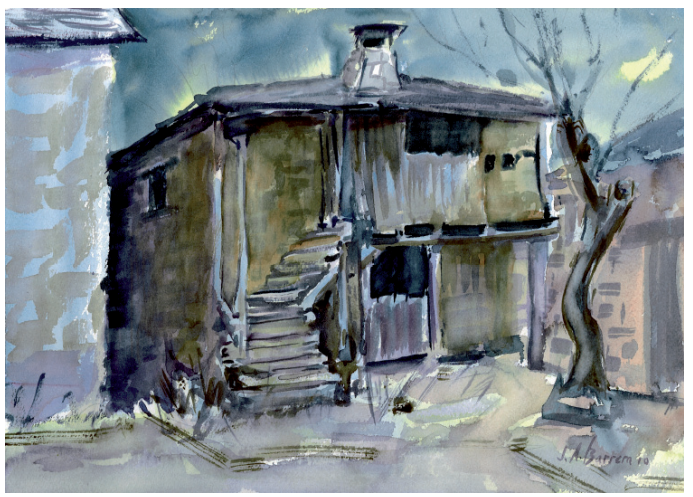

- Fig. 4. Acuarela de José Antonio Barrera. Paisajista a quien desde aquí agradecemos su cesión. 


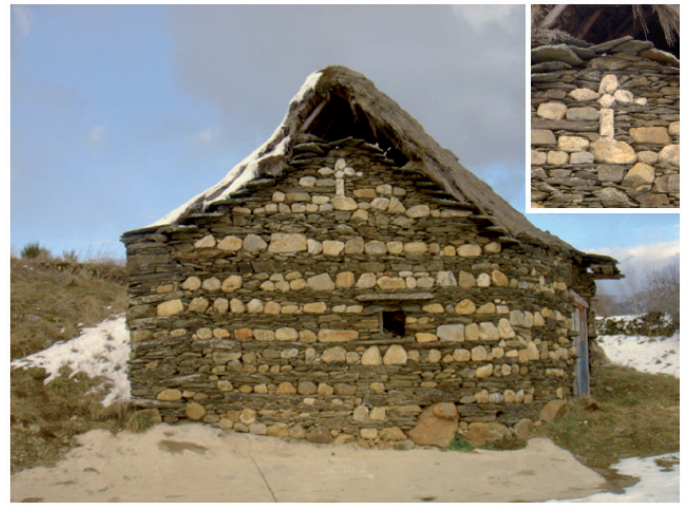

- Fig. 5. La bicromía de los cantos que forman los materiales pétreos de la zona se manifiesta en su estructura muraria. Es significativa la cruz hecha con las piedras blancas, que aquí, como en todas las construcciones auxiliares, son signos apotropaicos de protección, en este caso de la hierba necesaria para la alimentación del ganado

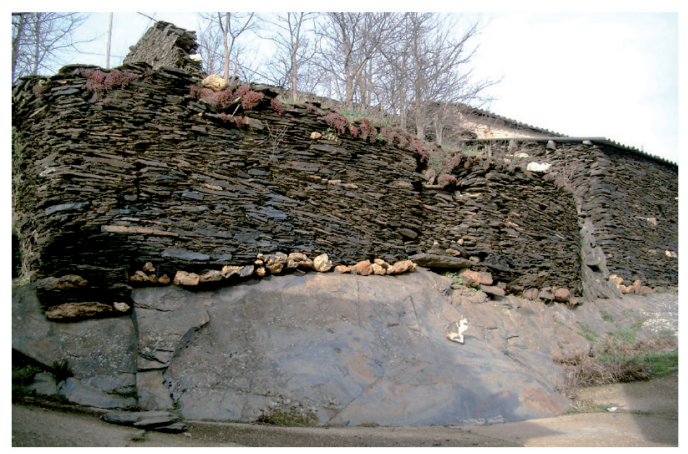

- Fig. 7. Cimentación natural. La pared, calzada con cantos rodados de cuarzo, escala la peña siguiendo el perfil sinuoso del suelo rocoso.

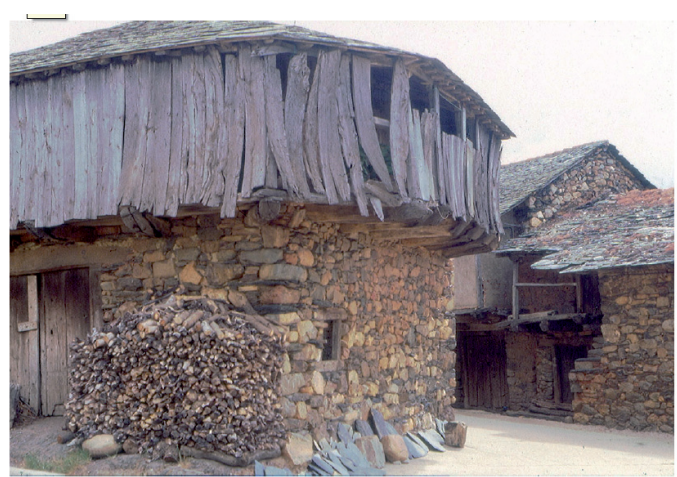

- Fig. 6. El corredor, generalmente de madera de roble o castaño, es elemento característico de la casa cabreiresa. Manifiesta su presencia desde el s. XVI. Se apoya sobre voladizos o sobre zapatas y pies derechos.

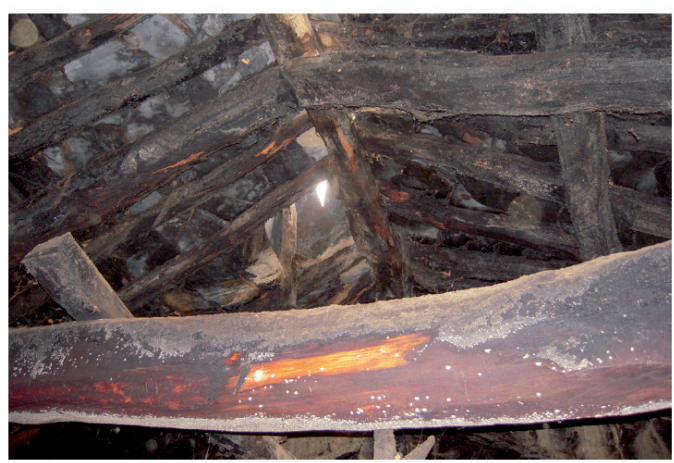

- Fig. 8. El modelo constructivo de estructura de cubierta. 


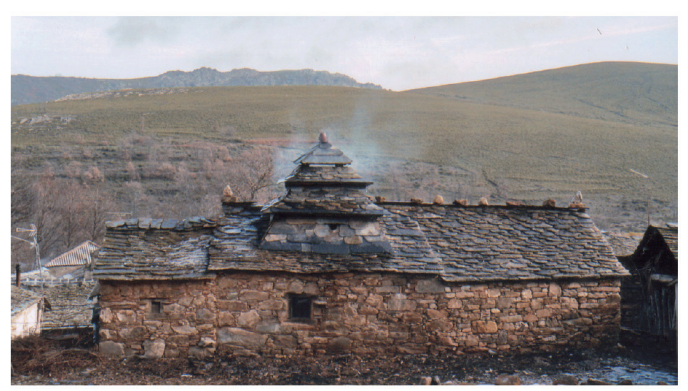

- Fig. 9. Chimenea troncopiramidal, cuarteada por el peso de los años, de tres cuerpos o pisos con remate piramidal sostenido, como las anteriores, por cuatro tacos de piedra.
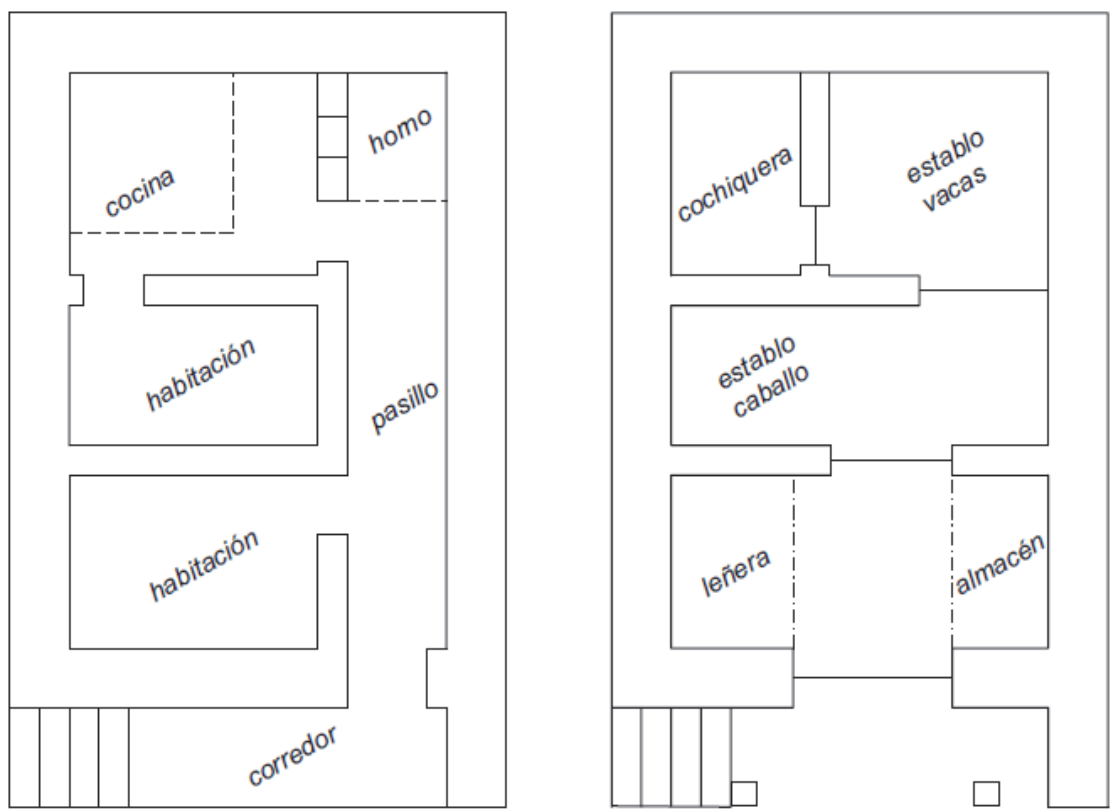

- Fig. 10. Corte al cuarto de perspectiva explosionada de vivienda tipo de dos pisos

- Fig. 11. Distribución en planta de las dos alturas de una vivienda tipo. 


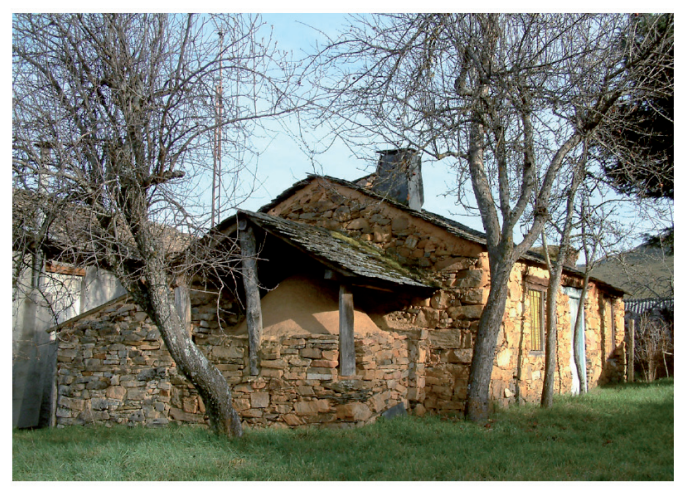

- Fig. 12. Los hornos se protegen de la intemperie por cobertizos levantados sobre pies derechos y ubicados en el corredor, en un caso y, en el otro, apoyado en una base cuadrada de piedra .

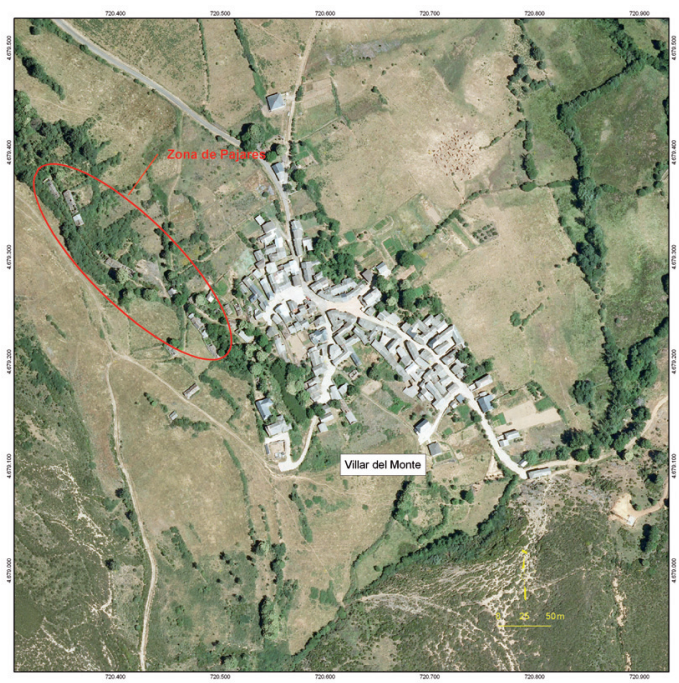

- Fig. 13. Ortofoto. Enclave de la zona de pajares alejada del núcleo poblacional

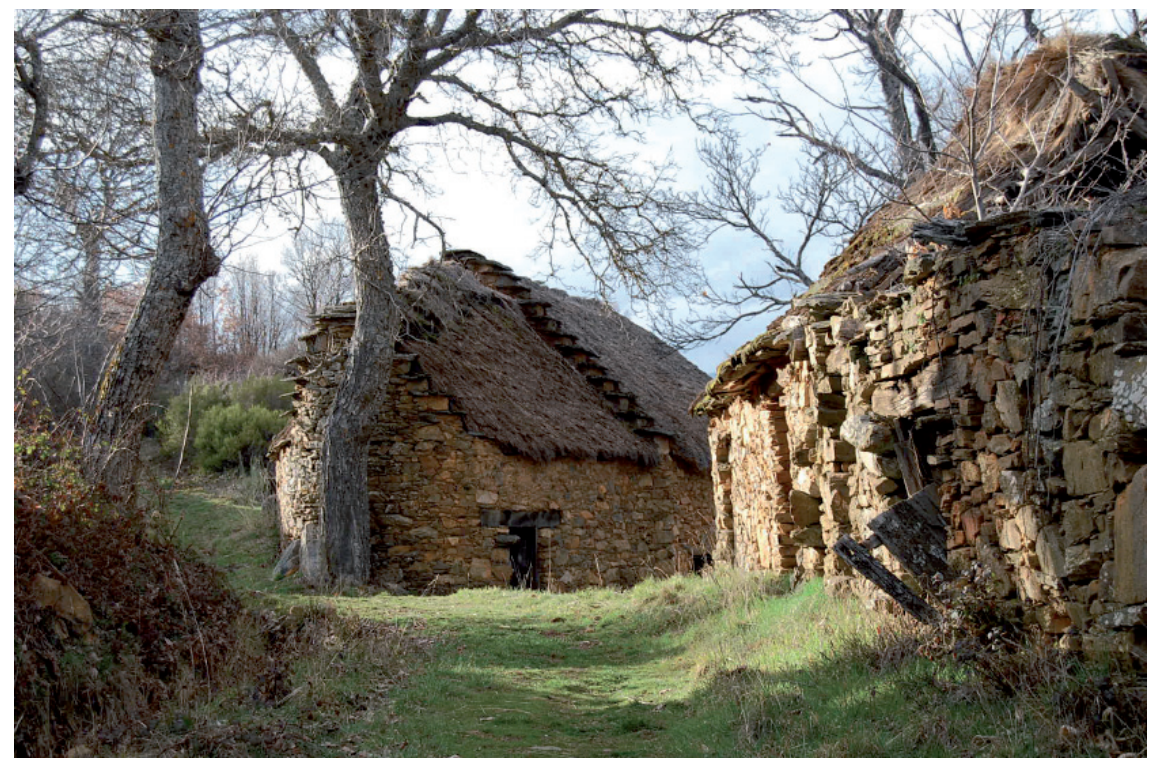

- Fig. 14. Geometría con trazados de fuertes pendientes que facilitan la evacuación rápida del agua y la nieve. 


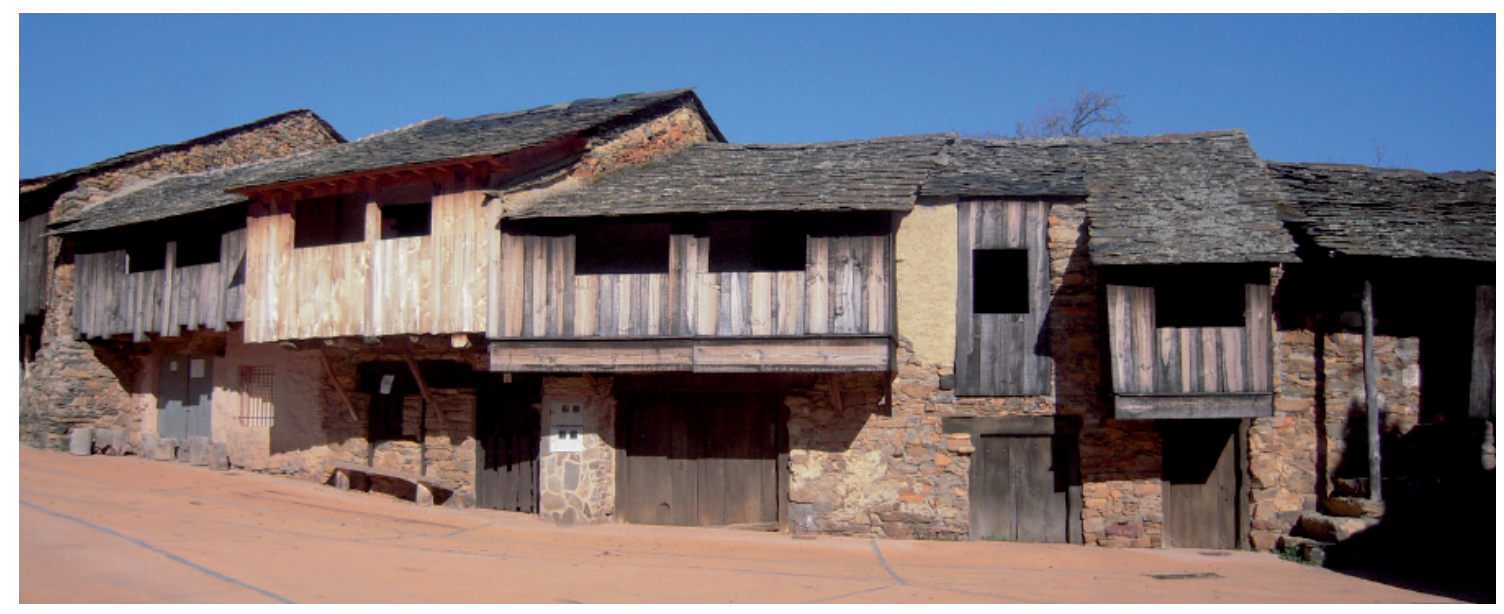

- Fig. 15. Villar del Monte. Recuperación del casco urbano con criterios de respeto a la cultura tradicional, desde las teorías de conservación y protección del patrimonio rural.

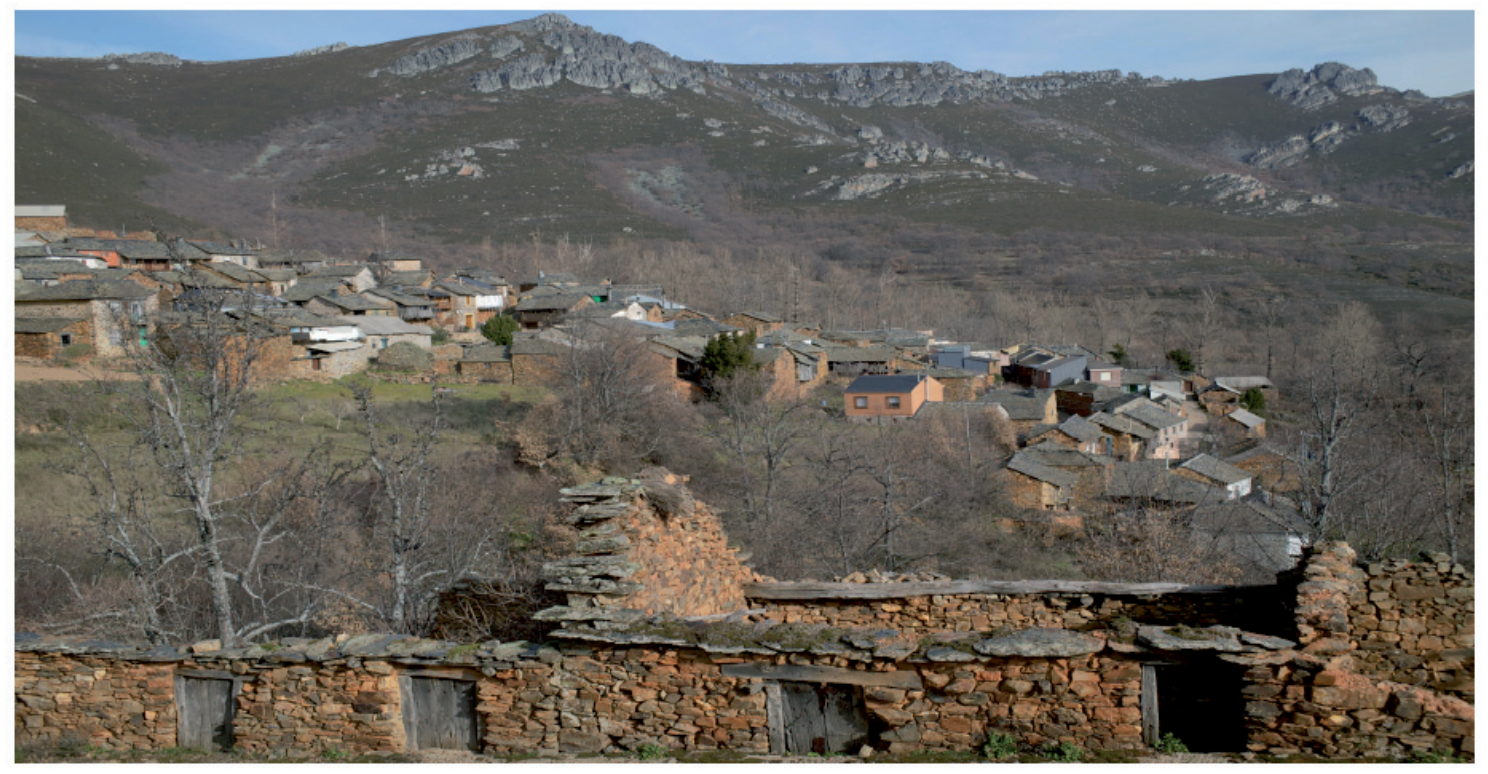

- Fig. 16. Barrio de pajares a las afueras de los pueblos y lejos de la vivienda, para evitar que en caso de incendio se pierda la cosecha. Equidistantes entre la vivienda y la cuadra. 